\title{
صعوبات النشر الأكاديمي (الملي والعربي والدولي) - المعوقات والحلول -
}

أ.م.د. أستعد شُربف الأمارة

قسبم علم الاهتما ع / كلية الآداب / جامعة واسط

\begin{abstract}
همدمهة:
عدت المر اكز البحثبـة والمؤسسـات الأكاديميـة (الجامعات و المعاهد العليـا) الر افد الأسـاس في تحديث المعلومات في العلوم الصرفة "البحتة" من خلال ما تنتجه من بحوث ميدانية أو نظرية بأساسها الفلسفي، فتطورت هذه المر اكز البحثية و الجامعات وقفزت قفزات نوعيـة بفضل نشر نتاجاتها التي وضعتها في مجلات دورية متخصصة وملخصات (Abstract) لبحوث محكمـة تنشر آخر مـا ينتج لها من علوم في نهاية كل عام، وفي جميع الاحوال فان هذه البحوث لابد وان يتم نشر ها وجعلها متاحة للآخرين لكي يتم الاستفادة منها والاضـافة عليها وبهذا فـان عجلـة التطور العلمي ستدور وتتطور
\end{abstract}

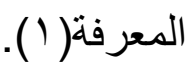

حتى أتسعت دوائر النشـر ولم تعد تستطيع أن تواكب كثرة النشريات ودقتها، وقدرتها على التوسع في الفروع الصغيرة من العلوم، ففي العلوم النفسية و الاجتماعية تشظت التخصصـات الدقيقة و أصبحت تبحث في كل مجـالات در اسـة الإنسـان، وكذللك الحسال في التـاريخ والجغر افيـة و العلوم الانسانية الأخرى، وشمل هذا التشظي العلوم الصرفة في الفيزياء وبمختلف فروعها و الكيمياء و علوم الاحياء و الرياضيات والجيولوجية، وكذلك في الطب وفروعه الدقيقة، و علم الامر اض و الأدويـة، هذا المجال الذي تداخلت فيه معظم أبحاث العلوم الصرفة و الانسانية والاجتماعية، فقدمت الجغر افية أفضل الخدمات لانتشار الظواهر في أصقاع العالم وعلاقتها في التأثثر البيئي والسكاني على الإنسان، وكذلك الفضل الكبير الذي قدمته العلوم الماليـة والإداريـة في أبحاثها النوعيـة عن حركة التسويق وأسـاليبه المتنو عة في حركة المجتمع وإدارة الجماعات وما تفضله في القبول، أو الرفض لهذا المنتوج أو تغيير اتجاهات الناس نحو المشاركة في العمليات الجمعية سو اء كانت بالسياسـة، أو العـادات الاجتماعية في تقبل المنتج، ويعرف أكثر منا من عمل في أبحاث علوم التسويق التجاري، وكيف تؤثر في العقل الجمعي من خلال تقبل الموضة، أو التهافت لمتابعة الرياضة وتسويق الوسائل الاعلامية الرياضية في إقتاع الملايين في الاشتراك بالقنوات الرياضية، إنها ثورة في العقل البحثي في كل مجالات العلوم، وليست ثورة في العقل النقلي كما يحدث لدينا الآن في بلداننا وبلدان العالم الثالث، هذه الكثرة الكاثرة من الأبحاث و الدراسات التي لم تعد المجلات الساكنة بتوقيتات دورية تعتمد النشر السنوي، أو النشر الحولي، أو النشر نصف السنوي، تجاوزت مر اكز الأبحاث والجامعات العريقة بنشرياتها النشر بهذه الطريقة، لتصبح البحوث المتخصصة الدقيقة أن تنشر كل شهر عدد يحتوي على آخر البحوث لثـر الثر 
نوفمبر مثثلا الذي يصل للمكتبـات في الايـام الثناثنة الأولى من بدايـة الثـهر، فضـلا عن المؤتمرات المستـمرة كل أسبوع في العـالم، و الحلقات البحثيـة (الســنار) عن موضـوع جزئي ربمـا أهمل في جامعاتنا، ولا نغالي إذا قلنا أن الحلقات البحثية "السمنرات" لم تعد في أقسامنا العلمية، إلا اللهم برامج در اسة الماجستير و الدكتور اه لتحديد عناوين بحثية لطلبة الماجستير و الدكتور اه فقط .

أن مؤسساتتا الاكاديمية أهملت تلك الموضو عات الصغيرة، ولم تعد تولي الاهتمـام بها، بينمـا أولت الجامعات والمر اكز البحثيـة والمعاهد العليـا، إهتمامًا عظيمًا بهذه الجزئيـات من در اسـة الوقـائع التاريخية و إنعكاساتها على المجتمع و السياسات في جميع الجامعات و المعاهد العليا ومر اكز الابحاث الحديثة، وضـعت المر اكز و الجامعـات اهتمامـاً عظيمًا بالحلقات البحثيـة "الســنر اته"، لأنها المدخل لأفكار جديدة وبحوث تنضج بعقل جماعي. أن النشر الأكاديمي في العالم المتقدم قد تجاوزنا بالنوع و الكم والدقة في التطور فهم مضو ا في الثورة في العقل، ونحن مضينا في الثورة بالنقل.

\section{احصائيسات عن النشر الدولي لابحوث الاكاديمية:}

يتفق الكثير مـن العلمـاء والبـاحثين في المؤسسـات الاكاديميـة في مختلف الجامعـات ومر اكز الابحـاث العالميـة أن النشر الاكاديمي هو هويـة المؤسسـة العلميـة، فعدد الأبحـاث ونو عيتها وحداثتها و مو اكبتها التطور في الاختصاص هو المعيار الذي يقاس به التقدم العلمي(ب). سأعرض بعض الاحصائيات عن النشريات في الجامعات والمر اكز البحثبـة والمعاهد العليا في مختلف دول العالم و عند مقارنتها مع وضعنا الحالي نكون قد وضعنا أنفسنا في المو اقف الحرجة لا من حيث العدد أو الجودة، بل من حيث مو اكبتها للتحديث المستمر في العالم. أن الو لايات المتحدة الأمريكية تحتل صدارة دول العـالم في عدد الأبحاث التي تم نشرها في دوريات عالمية محكمة دولياً بعدد ما يقرب من خمسـة ملايين بحث تلتها الصين في المرتبـة التانية بعدد ^. ا مليون بحث ثم بريطانيا بعدد هـ 1 مليون بحث ثم اليابـان في المرتبـة الر ابعـة بعدد ع. 1. مليون بحث فألمانبـا في المرتبـة الخامسـة بعدد وس. ا مليون بحث. في حين احتلت مصـر المرتبـة الأربعون بحو الي 10 ألف بحث دولي. هذه المرتبة المتأخرة لمصر مقارنـة بعدد من الدول النامية و التي بدأت مر احل التنمية الثاملة في منتصف القرن الماضـي مثل الهند (المرتبـة العاثـرة بعدد سبه ألف بحث دولي) و البرازيل (المرتبة الخامسة عشر) وايران (المرتبة الواحد والثناثين) والأرجنتين (المرتبة السادسة والثلاثثن) أو بدول صغيرة في عدد السكان مثل فنلندا و التي يصل عدد سكانها إلى ولى حو الى اربعة ملايين نسمة فقط (المرتبة الخامسة والعشرون) يعكس مدى تردى وضـع البحث العلمي في مصر كدولة رائدة و عريقة، وييرز ضرورة الاهتمام بالبحث العلمي في المستقبل القريب كأحد 
ركائز التنمية و التقدم في مصر( ( ) وربما غابت الاعداد الحقيقية في بعض الدول العربية الاخرى، أما لضآلة أعدادها، أو عدم وجود إحصائيات دقيقة عنها. و الجدول التالي يوضح الدولة و عدد الأبحاث و المرتبة بالعالم.

\begin{tabular}{|c|c|c|}
\hline المرتبة & عدد الابـاث & الدولة \\
\hline 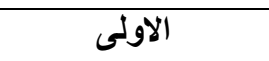 & أكثر من خمسة ملايين بحث & الولايات المتحدة الامريكية \\
\hline الثانية & 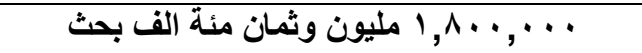 & 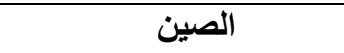 \\
\hline 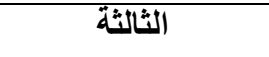 & 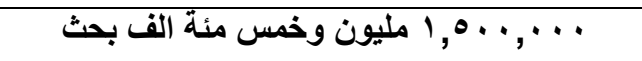 & المملكة المتحدة \\
\hline الرابعة & 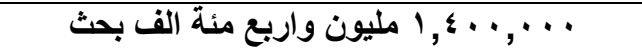 & اليابان \\
\hline 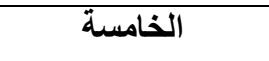 & 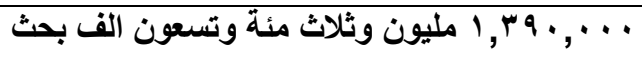 & المانيا \\
\hline العاشرة & 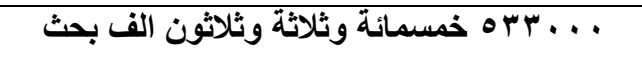 & الهند \\
\hline الخامسة عشر & - & 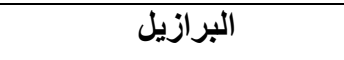 \\
\hline الخامسة و العشرون & - & فتلندا \\
\hline الواحد والثلاثين & - & ايران \\
\hline السادس والثلاثين & - & الارجنتين \\
\hline الاربعون & 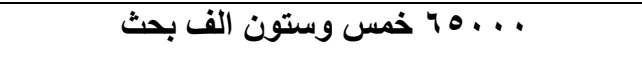 & جمهورية مصر العربية \\
\hline
\end{tabular}

هما الذي يمققه النشر الأكاديمي؟

تكمن أهمية النشر العلمي في مدى إيصاله إلى من يستفيد منه لأن كميته تكمن في وجود النشر الجيد حيث يتجلى ذلك من خلال الآتي: ا ـ المساهمة الفاعلة في تطوير طرق وأساليب العمل لدى الأفر اد والمؤسسات من خلال الإطلاع على كل ما هو جديد. r- تنشيط حركة البحث العلمي. ب- معرفة رصانة البحث العلمي من خلال معرفة عدد الإشار ات إلى البحوث المنشورة في الدراسـات الأخرى. ع- تتمية الوعي العلمي بضرورة البحث العلمي بين أفر اد المجتمع على أوسع نطاق.

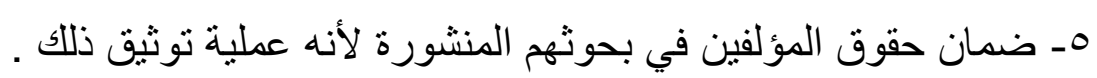
ד- المساعدة في تجنب تكرار أجراء البحوث نفسها(ب). Vـ التو اصـل مـع حركة التحديث في المجـالات العلميـة الأكاديميـة المتخصصـة في جميع مؤسسـات البحث العلمي و الجامعات ومر اكز الأبحاث. 1ـ الانفتـاح على العـالم في مجـال البحث الاكـاديمي المتخصص والاثـتر الك في الجمعيـات العلميـة المتخصصة. 


\section{بعض الصعوبات التي تواجه النشر الأكاديمي والهلول الواقعية لها:}

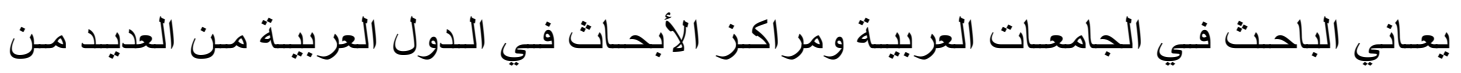
الصعوبات في النشر و الاشتر الك و المساهمة في العضوية الفاعلة منها:

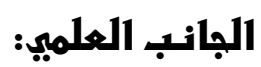

ا ـ قلة المجلات العلمية المتخصصة في العلوم الدقيقة. r- ضعف الموضو عية لدى بعض المحكمين وضعف قو انين الححاسبة لهم. r- عدم وجود معايير موحدة في تقييم الأبحاث في المجلات العلمية العربية .

الجانب الإداريى والمالي والتنـظيمي: ا - عدم تفرغ العاملين في مجال إدارة المجلة العلمية الأكاديمية ( تفتقر لعمل المؤسسة). r- البيروقر اطية في إدارة المجلة أو إجر اءات الجامعة أو مر اكز الأبحاث.

rـ ضعف التو اصل بين إدارة المجلة و المجلات العلمية العالمية التي أصبحت مؤسسات قائمة بذاتها. ع- ضعف تو اصل الباحثين واساتذة الجامعات في العراق و الدول العربية مع المجلات البحثية العلميـة و الجمعيات العالمية التي أصبحت مر اكز استقطاب لكل باحث أو أكاديمي داخل البلاد أو خارجهـ. ويحق لكل باحث من جميع أنحاء العالم أن يشترك في عضوية المجلة والجمعيات المتخصصة. هـ تحقق المجلة موارد مالية مستقلة تدخل ضمن ميز انيـة الجامعات أو مر اكز الأبحاث حتى بـات

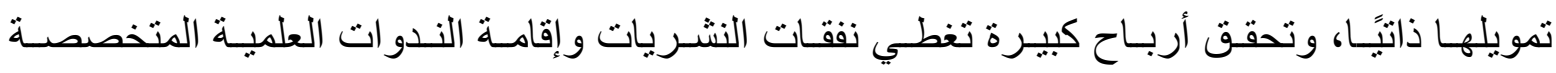
و إصدارات المجلات و الكتب و الكتيبات ذات الفصل الو احد. مثال بسيط على ذلك (الندوة المقامة حاليًا في كلية الآداب هي من عوائد مجلة لار الك.. ابسط مثال و اقعي في إدارة المجلات العلمية، فكيف إذا كانت عشرة مجالات علميـة أو أكثر تديرها إدارة متفرغة بمختلف الاختصاصات العلمية وتستطيع التو اصل مع شبكة وكلاء في العالم.. مثال و اقعي آخر مر بـه الباحث: في احدى الجامعات الأوربية كنت أتصفح الدوريات داخل المكتبة فوقع بين يدي مجلة Education Studies تصدر في أوسلو - النرويج، ارسلت رسالة

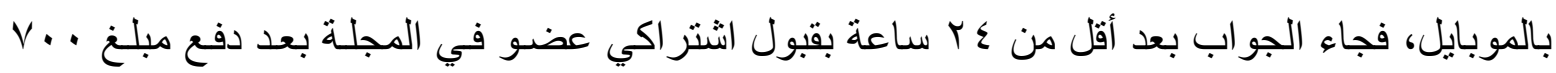

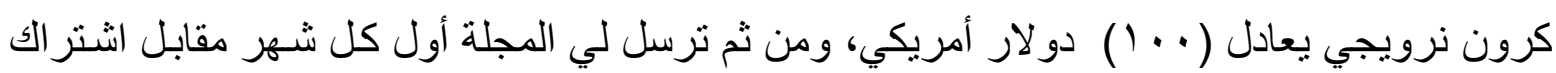

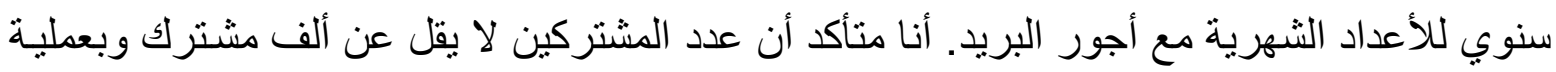

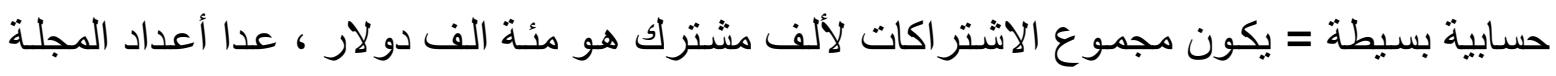


السنوي الذي لا يقل عن (• () عشرة دو لارات ثمن كل عدد = • با دولار سنويًا لكل مشترك وهذا

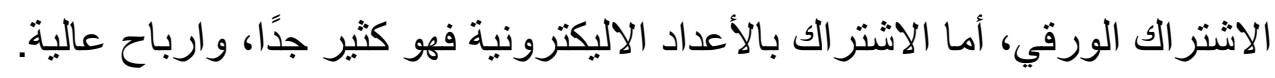

\section{خاتمة:}

المجلة و الجمعيات المتخصصة ومر اكز الأبحاث في الجامعات تحقق:

ا - تواصل علمي مع جميع المؤسسات الاكاديمية " الجامعات و المعاهد العليا"

r- التو اصل مع الباحثين في مختلف دول العالم من العاملين في المجالين: البحثي "البحوث و الحلقات

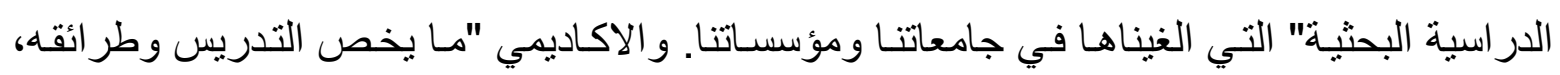
و المناهج وتطوير مهار ات الطالب".

r- الجو انب المالية وما تحققه المجلات العلمية المتخصصة و الاشتر اكات بعضويتها. عـ العو ائد المالية للمبيعات المتحققة لأعداد المجلة الدورية، وحلقات البحث العلمي" السمنر" ومجلدات البحوث المنشورة في المؤتمرات.

هـ العمل على زيادة موارد الجامعات من خلال البحث عن طرق أخرى لتمويل الجامعات وأجهزتها

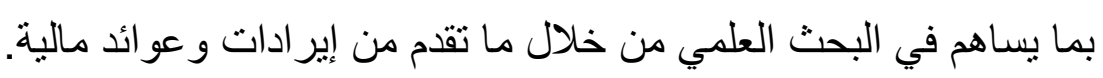
7ـ دعم دور النشر الجامعية والدجلات العلمية والنظر إلى عملية النشر الجامعي على أنه نشاط رئيس من أنشطة الجامعات علميًا وماليًا. V- العمل على الاستقلال المالي و الإداري للمجلات العلية وعو ائدها المالية. 1- ضرورة التخلص من الإجراءات البيروقر اطية " الإداريـة والمالية" داخل الجامعات و المؤسسـات البحثية الأكاديمية في العراق.

9ـ لكي يصبح الأكاديمي العر اقي عالمي عليه أن ينو اصل ويشترك بالجمعيات العلمية المتخصصـة

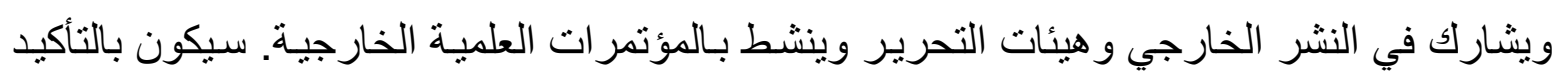

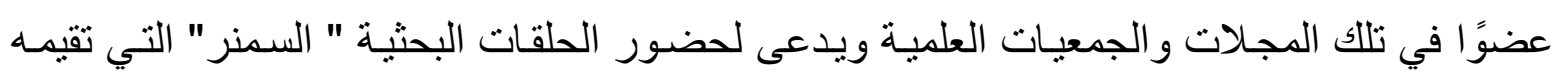
المجلات العلمية لغرض تسويق أفكار البحوث الجديدة بإصدارات علمية ورقيه و اليكترونية.

المادر :

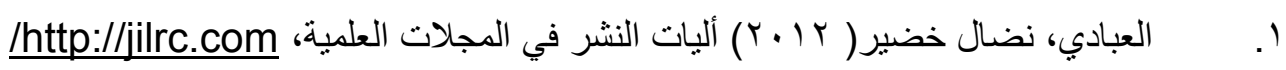

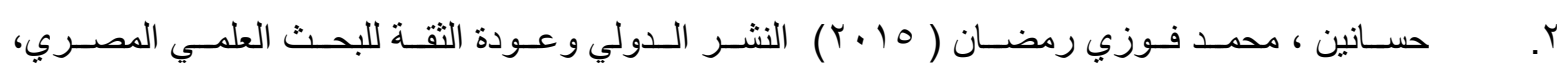
http://www.arsco.org

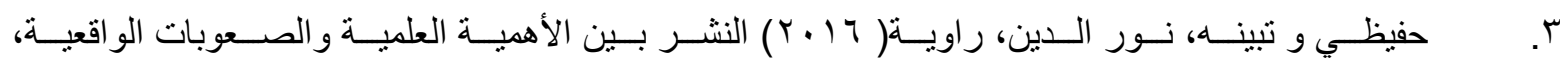
/http://jilrc.com 